\title{
Particle processing mechanisms of the eulamellibranch bivalves Spisula solidissima and Mya arenaria
}

\author{
Peter G. Beninger *, Suzanne C. Dufour, Julie Bourque \\ Département de biologie, Université de Moncton, Moncton New Brunswick, Canada E1A 3E9
}

\begin{abstract}
To date, the marine eulamellibranch gill type is the only one of the 4 principal bivalve gill types whose mechanisms of particle processing have not been thoroughly investigated using the contemporary techniques of endoscopy and determination of mucocyte distribution. To this end, particle handling on the pallial organs (gills, palps, lips, mantle) of Spisula solidissima and Mya arenaria was examined using endoscopy and histology, as well as half-shell preparations. In both species, all particles intercepted by the gill were transported ventrally to the gill particle groove and then anteriorly to the labial palps. Rejected particles (i.e. pseudofaeces) were shunted to the palp ventral margin, and thence posteriorly to the palp tip and ultimately to the mantle. Pseudofaeces were transported along a narrow, distinct pathway on the ventral margin of the mantle to the inhalent siphon. It is postulated that such a pathway is characteristic of bivalves possessing a single gill particle groove and siphons. The transport medium for particles on the gill was acid mucopolysaccharides (AMPS). This conforms to an emerging pattern for counter-current particle transport on exposed surfaces. Examination of mucocyte distribution and residual AMPS suggests that in $M$. arenaria, and perhaps also $S$. solidissima. AMPS is secreted onto the gill filament frontal surface from cells remotely located on the lateral faces of the filament. Although $S$. solidissima also presents mucocytes on its frontal surface, its lateral mucocytes are much more developed. In $M$. arenaria, mucus-particle masses destined for ingestion were mechanically fluidized by the labial palps. The presence of mucocytes containing neutral-mucopolysaccharide in the gill particle groove suggests that there may also be a biochemical component to fluidization. It was not possible to observe palp treatment of particles destined for ingestion in S. solidissima. Ingestion volume control was effected in both species at 2 levels: closure of the gill particle groove, and closure of the lower lip of the mouth. Although few differences in pseudofaeces pathways were observed between specimens examined endoscopically and in half-shell preparations, the latter were not suitable for study of particle processing for ingestion.
\end{abstract}

KEY WORDS: Feeding - Bivalves - Mechanisms - Eulamellibranchs · Spisula $\cdot$ Mya

\section{INTRODUCTION}

Through their suspension-feeding activity, bivalve molluscs may profoundly influence aquatic ecosystems, notably via biodeposition, nutrient recycling, and plankton grazing (Winter 1978, Dame et al. 1980, Jørgensen 1990). Similarly, the increasing importance of bivalve aquaculture underscores the need for a comprehensive understanding of feeding in these organisms.

·E-mail: beningp@bosoleil.ci.umoncton.ca
A considerable and persistent research effort over the past $10 \mathrm{yr}$ has elucidated many heretofore elusive aspects of bivalve suspension-feeding mechanisms. Breakthroughs in this field have been made possible with the development of in vivo video endoscopy, combined with fluid sampling and subsequent chemical and histochemical analyses (Ward et al. 1991, 1993, 1994, Beninger et al. 1992, Tankersley \& Dimock 1993, Beninger \& St-Jean 1997, in press), histology and mucocyte mapping (Beninger et al. 1991, 1993, Beninger \& Le Pennec 1993, Beninger \& Dufour 1996, Beninger \& St-Jean 1997, in press), and most recently confocal laser microscopy on living gill fragments 
(Silverman et al. 1996, Beninger et al. in press). Notwithstanding recent unsubstantiated objections (Jørgensen 1996), the convergent results of these complementary methodological approaches demonstrate unequivocally the implication of different mucus types in particle transport and subsequent processing, both for normal feeding and for rejection.

The gill is the initial site of particle capture and subsequent transport in suspension-feeding bivalves. To date, 3 of the 4 basic bivalve gill types have been studied in detail: homorhabdic filibranch, heterorhabdic filibranch, and heterorhabdic pseudolamellibranch. Some aspects of the function of the homorhabdic eulamellibranch gill have been examined using video endoscopy; however, these observations were quite cursory (Ward et al. 1993). The eulamellibranch gill of Pyganodon cataracta has also been studied using video endoscopy (Tankersley \& Dimock 1.993), but this is a freshwater species whose gills are adapted for brooding Subsequent treatment of particles by the other pallial organs has been presented for Crassostrea virginica, representing the heterorhabdic pseudolamellibranch type (Ward et al. 1994) and for Mytilus edulis, representing the homorhabdic filibranch type (Beninger \& St-Jean 1997); these studies did not include examination of the mantle

The present study investigates the transport and processing of particles on the various pallial organs of 2 eulamellibranch bivalve species: Mya arenaria (Fam. Myacidae) and Spisula solidissima (Fam. Mactridae). Two observational techniques were used: video endoscopy of intact individuals and deposition of inert carmine particles on the pallial organs of dissected specimens, allowing comparison of particle treatment in the 2 conditions. In addition, histological studies of the gills of both species were performed in order to determine the locations and types of mucocytes present.

\section{MATERIAL AND METHODS}

Sampling and specimen maintenance. Adult specimens of Spisula solidissima $(12.3$ to $15.7 \mathrm{~cm}$ shell length) were obtained via SCUBA in Shediac Bay, New Brunswick (46. $17^{\prime} 25^{\prime \prime} \mathrm{N}, 64^{\circ} 32^{\prime} 15^{\prime \prime} \mathrm{W}$ ), Canada, in July 1995, and from the Centre Marin de Shippagan, New Brunswick, in November 1995. Each lot of $S$. solidissima was placed in refrigerated, recirculating, artificial seawater at temperatures and salinities corresponding to those measured at the sampling sites. To reproduce as closely as possible the natural environment, each individual was allowed to burrow into sand contained in flower pots within the aquarium and exposed to the normal photoperiod. The specimens were fed 2 to 3 times weekly using the algal paste Diet $C$ (Coast Seafoods Co., Quilicene, WA, USA), which consists of a mixture of Thalassiosira pseudonana, Chaetoceros calcitrans, Skeletonema sp., and Tahitian Isochrysis luther.

A total of 4 specimens were used for endoscopic observation. All specimens appeared well-adapted to the aquarium environment (embedded in sand, siphons extended, normal current flow established)

Adult specimens of Mya arenaria (8.7 to $10.2 \mathrm{~cm}$ shell length) were obtained at low tide on a tidal mudflat in Passamaquoddy Bay. New Brunswick (45 6 $6^{\prime} 25^{\prime \prime} \mathrm{N}$, $65^{\circ} 3^{\prime} 25^{\prime \prime} \mathrm{W}$ ) in January 1996. They were maintained in a refrigerated aquarium as above; since these specimens began to feed normally soon after being placed in the aquarium, it was not necessary to place them in containers of sediment.

The mantle of Mya arenaria is completely fused, with the exception of the inhalent and exhalent siphons. It was therefore necessary to make a small perforation using a white-hot $1.7 \mathrm{~mm}$ copper wire in the ventro-anterior region, as described in Ward et al. (1991) in order to allow introduction of the optical insertion tube (OIT). The 6 specimens were allowed to recover for at least $1 \mathrm{wk}$ prior to endoscopy. All such individuals displayed normal, relaxed behavior commencing the day of the perforation (siphons and tentacles extended, particles taken into pallial cavity when presented via Pasteur pipette), and all were behaviorally indistinguishable from non-perforated $M$. arenaria in the aquarium for the following 5 mo of experimentation.

Endoscopy. The endoscopic system consisted of an Olympus endoscope and C-mount adapter (K-17-1800-72 Olympus, Markham, Ontario), a variable-intensity light source (Olympus ALS-6250U), a miniature black-and-white CCD video camera and remote console (Cohu Electronics, San Diego, CA), and a micromanipulator and custom-made support (Fig. 1) The magnification obtained from this system was inversely proportional to the distance between the subject and the distal extremity of the OIT, to a maximum of $20 \times$ (instrument specifications).

Specimens were placed on an inclinable platform within a 251 bucket kept in the aquarium to maintain a constant temperature. Seawater within the bucket was gently circulated and aerated using an airstone. Individuals to be used for endoscopy were allowed to acclimate to the platform for several hours prior to insertion of the OIT of the endoscope, and again for several hours after insertion. Recording began when the animal appeared completely relaxed (siphons extended, tentacles deployed, normal pallial cavity current flow and particle movement established). Each recording session lasted approximately $2 \mathrm{~h}$. During 


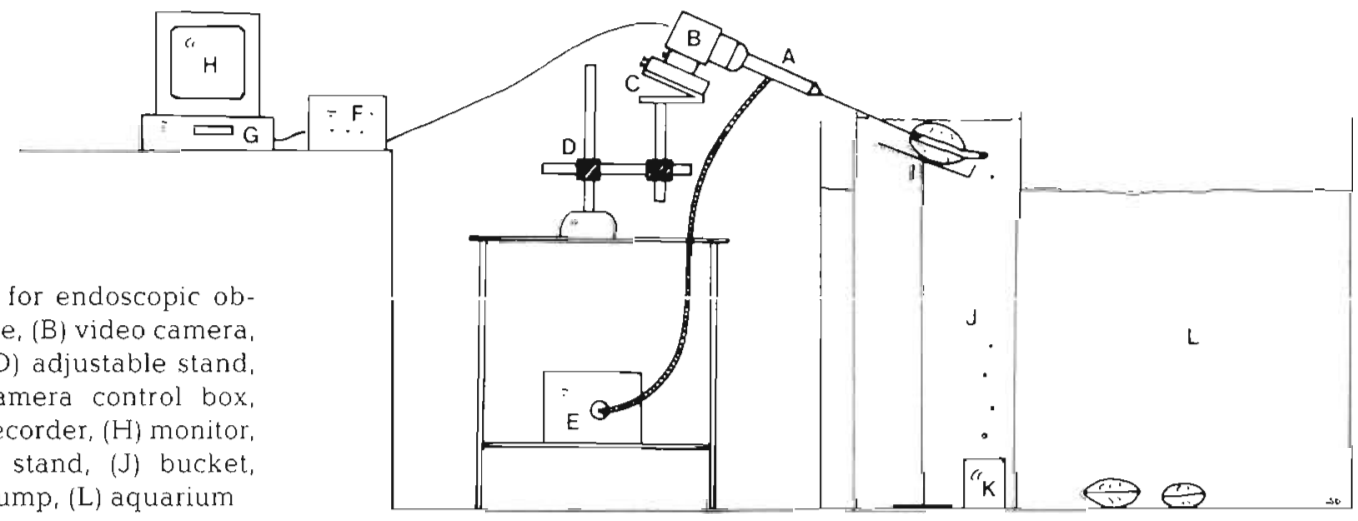

Fig. 1 Equipment used for endoscopic observations. (A) Endoscope, (B) video camera (C) micromanipulator, (D) adjustable stand (E) light source, (F) camera control box (G) $\mathrm{Hi}$-8 video cassette recorder, $(\mathrm{H})$ monitor (I) inclinable specimen stand, (J) bucket (K) water-circulating pump, (L) aquarium lamellae. A qualitative histological assessment of the mucocyte types and distributions was therefore undertaken.

Three specimens of Spisula solidissima were obtained from the intertidal at Cap Pelé, New Brunswick (46 $\left.16^{\circ} 20^{\prime \prime} \mathrm{N}, 64^{\circ} 15^{\prime} 55^{\prime \prime} \mathrm{W}\right)$ in June 1996. Their adductor muscles were sectioned and the whole specimens were immediately fixed in aqueous Bouin's solution. Three specimens of Mya arenaria were similarly obtained at Grande Digue, New Brunswick $\left(46^{\circ} 18^{\prime} 15^{\prime \prime} \mathrm{N}, 64^{\circ} 32^{\prime} 30^{\prime \prime} \mathrm{W}\right)$ in July 1996 and fixed in the same manner. The gills of both species were rinsed with running water for $12 \mathrm{~h}$, then divided into 3 regions along the antero-posterior axis (anterior, middle, posterior) and 3 regions along the dorso-ventral axis (dorsal, middle, ventral) using micro-surgical instruments. The gill portions were dehydrated and processed for paraffin histology, sectioned at $10 \mu \mathrm{m}$ (mean mucocyte diameter), and stained using the PAS-alcian blue technique (Beninger et al. 1993), with the following staining times: $1 \%$ alcian blue $8 \mathrm{GX} 25 \mathrm{~min}, 1 \%$ periodic acid $5 \mathrm{~min}, 50 \%$ Schiff reagent (Fisher Scientific) $5 \mathrm{~min}, 0.5 \%$ sodium metabisulfite $5 \mathrm{~min}$.

The lack of any mucocytes in the epithelium of the gill frontal surface of Mya arenaria prompted an intensive search throughout the gill, from the gill arch to the ventral particle groove and from the anteriormost to the posteriormost filaments

\section{RESULTS}

\section{Particle concentration}

of the external demibranch, and the particle trajectory was observed using a Leica dissecting microscope with fibre-optic illumination.

Histology. Preliminary attemps to quantify mucocyte distribution using in toto staining (Beninger et al. 1993) were unsuccessful. on the gills of both species, due to the extreme degree of intra-lamellar and interfilamentar fusion in the eulamellibranch gill, which prevented separation of the ascending and descending
In both open and closed systems, particle concentration is dynamic, due to variable clearance and evacuation in open systems, and to variable clearance and microbial proliferation in closed systems. In the closed system of the present work, microbial proliferation imposed a minimum baseline concentration of particles $>1 \mu \mathrm{m}$ of $8 \times 10^{3} \mathrm{ml}^{-1}$, which is in the low range 
for seawater (Atlas \& Bartha 1987). Marine eulamellibranchs can intercept particles of 1 to $2 \mu \mathrm{m}$ with 40 to $50 \%$ efficiency (Riisgård 1988), whereas the ingestion and utilisation of bacteria has been demonstrated in 3 freshwater eulamellibranch species (Silverman et al. 1995). Given these considerations, we decided to include all particles $>1 \mu \mathrm{m}$ in the determination of final particle concentration after addition of algae and reflective particles. The particle concentration for all observations was thus approximately 20 to $40 \times 10^{3} \mathrm{ml}^{-1}$; correcting for the inclusion of particles $<4 \mu \mathrm{m}$ brings this into the medium particle concentration range previously used for endoscopy of 4 bivalve species, including Mya arenaria (Ward et al. 1993).

\section{Endoscopy}

\section{Spisula solidissima}

The natural architecture of the gills was readily visible with the OIT in place. Individual filaments and plicae were easily observed, as well as the ventral particle grooves. In the anterior region, the natural configuration of the labial palps was visible on either side of each demibranch (Fig. 2). The anterior extremities of the demibranchs were free, and extended almost to the mouth (Fig. 3.5, 3.6). Both the palps and the gills showed movement within the pallial cavity, but the palps were much more dynamic, being in nearconstant motion. As the gills of Spisula solidissima were much wider (dorso-ventral axis) than the labial palps, each member of a labial palp pair was separated from its corresponding member by the gill lamella, precluding any contact between the labial palps (Fig. 2).

Suspended particles approaching the gill were intercepted and transported ventrally along the frontal surface to the particle groove, where they were incorpo-

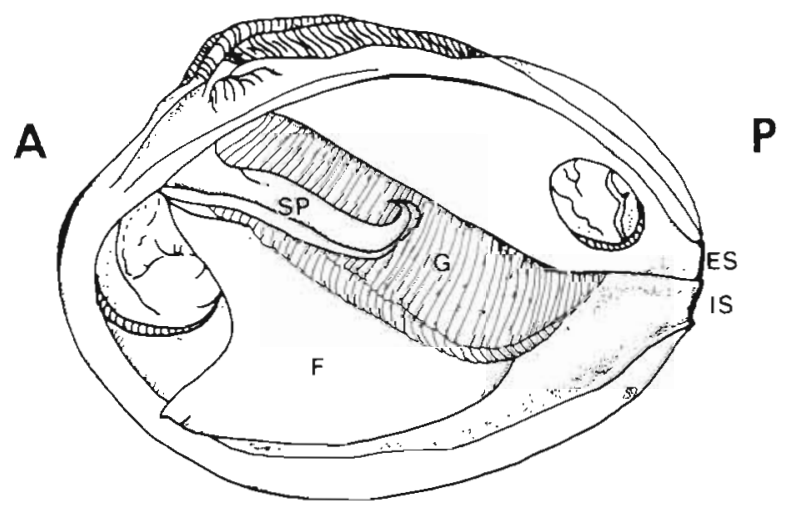

Fig. 2. Spisula solidissima. Diagram of a specimen with left valve and mantle removed. A: anterior extremity; ES: exhalent siphon; F: foot; G: gill; IS: inhalent siphon; A: anterior extremity; P: posterior extremity; SP: smooth palp surface rated into a mucus cord moving anteriorly to the labial palps (Fig. 3.1, 3.2). After prolonged feeding, the particle groove often closed entirely, preventing the entry of any additional particles from the gill; these particles continued anteriorly a short distance along the obstructed groove and then were either re-suspended in the pallial cavity prior to arrival at the palps, passed onto the palps or re-suspended in the pallial fluid between the palps. Particles were never observed travelling either dorsally along the filaments, or anteriorly in the gill arch or dorsal bend.

Transfer from the gill particle groove to the labial palp was not observed in this species, nor were the initial stages of particle processing for ingestion or rejection. However, the opening and closing of the lower lip was observed in the buccal region (Fig. 3.5, 3.6). The latter stages of pseudofaeces rejection were also observed: after prolonged feeding, mucus-particle cords exited the palp troughs and joined a rejection cord travelling posteriorly along the ventral palp margin. This cord occasionally detached from the ventral margin ciliated tract, and was forced onto the ventralmost regions of the palp crests by the dorsalward flow of fluid in the pallial cavity. Upon contact, these regions rapidly contracted and relaxed, pushing the mucus-particle cord of pseudofaeces back onto the ventral ciliated (rejection) palp tract (Fig. 4.5, 4.6).

\section{Mya arenaria}

Endoscopic observations confirmed that in the natural state, filaments of the external demibranch are approximately $20 \%$ shorter than their counterparts on the internal demibranch, as indicated in Atkins (1937). The palps of Mya arenaria were wider and shorter than those of Spisula solidissima, and extended beyond the gill in the dorso-ventral plane. Consequently, the members of each labial palp pair were very tightly appressed in the natural state (Fig. 4.1). This natural conformation imposed an important limitation to observation and interpretation: visualisation of particle processing between the palps was only possible by separating the palps with the OIT, and this procedure probably interfered with normal particle handling. As a result, only the most convincing observations will be reported here, and some aspects cannot be dealt with at all.

As was observed for Spisula solidissima, suspended particles in Mya arenaria were intercepted by the gill and directed ventrally along the filament frontal surfaces to the particle groove, where they were incorporated into a mucus-particle cord (Fig. 5). This cord continuously moved anteriorly toward the palp region; there, the cord detached from the gills onto the ridged 
Fig. 3. Spisula solidissima and Mya arenaria. Pallial organs viewed via endoscopy. Due to the 3-D character of the images, no scale bars are indicated. (3.1) Frontal surface of gill (G) of $S$. solidissima, showing gill particle groove (GPG). Arrow indicates the anteriorward movement of mucus-particle masses in the groove. (3.2) View of gill particle grooves (GPG) of S. solidissima, with mucusparticle cord being transported anteriorly (arrow). (3.3, 3.4) Mucus cord (MC) being transferred from gill particle groove (GPG) to ridged palp surface (RP) of $M$ arenaria. Arrowheads indicate areas where palp ridges are inclined anteriorly. Mucus bridge is much more visible in video sequences. $(3.5,3.6)$ View of buccal region of $S$. solidissima, with gills (G) and ridged palp surface (RP) visible. Lower lip (LL) is retractable (arrow)
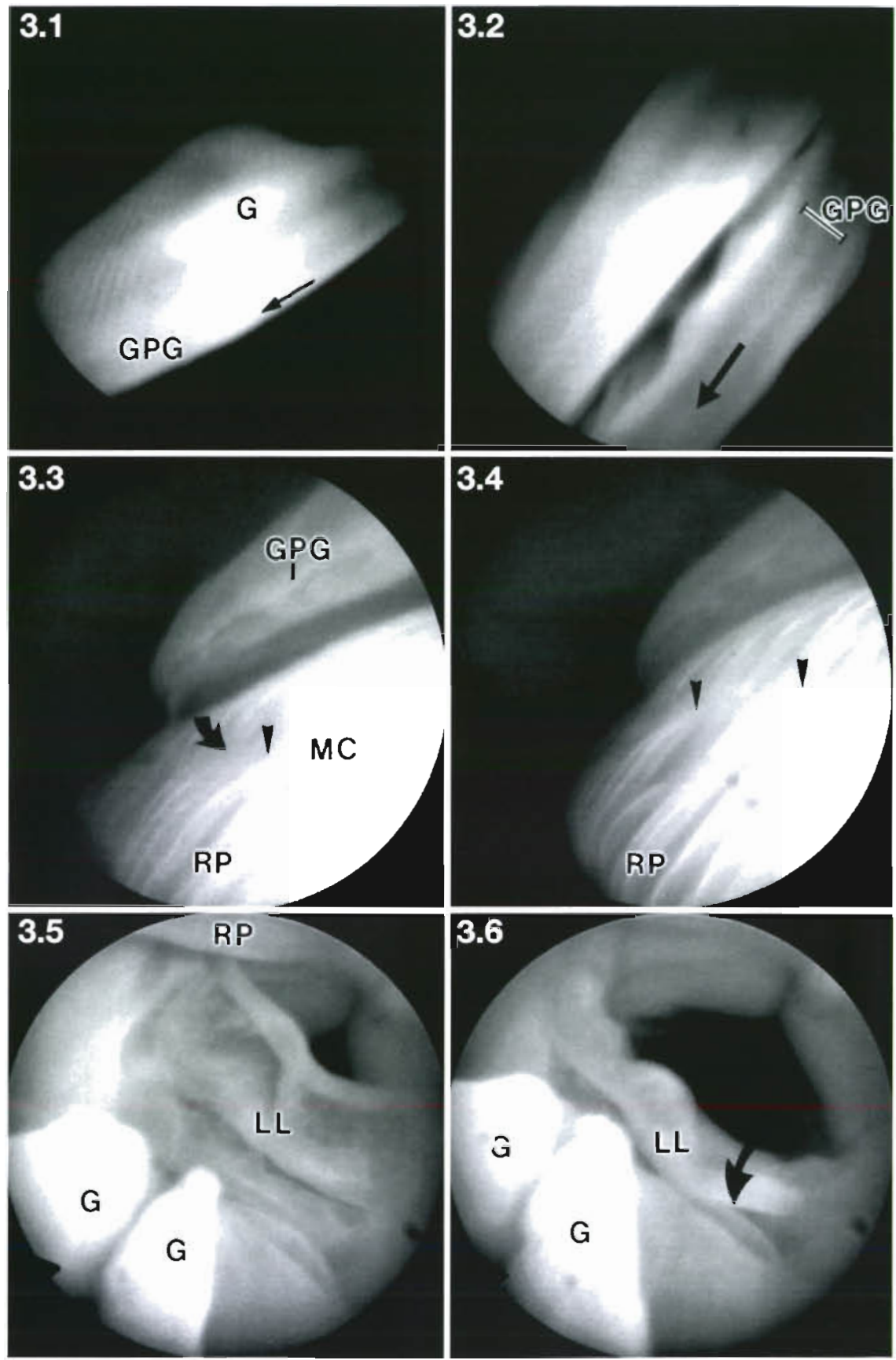

surface of the palps (Fig. 3.3, 3.4). Detachment occurred at several different points along the gill ventral particle groove. As was observed in Spisula solidissima, the gill particle groove often closed after prolonged feeding, with the same consequences for additional particles arriving from the gill.

Two types of particle treatment were observed on the Mya arenaria labial palps: processing for ingestion and processing for rejection. Material to be ingested was moved anteriorly at right angles to the palp ridges, within successive temporary depressions of the ridge crests (Fig 6.1). There was no fixed locus for the formation of such ephemeral tracts. As the mucus-particle cord travelled anteriorly to the mouth from one palp crest to the next, it was subjected to mechanical forces applied by the apposition and grinding motion of both palps. Although the cord was not visible when both palps were applied, material which re-appeared further anteriorly was fragmented and flocculent. All material in the buccal region was present in the form of a mucus-particle slurry, indicating that disassembly and fluidization occurred progressively from arrival on 

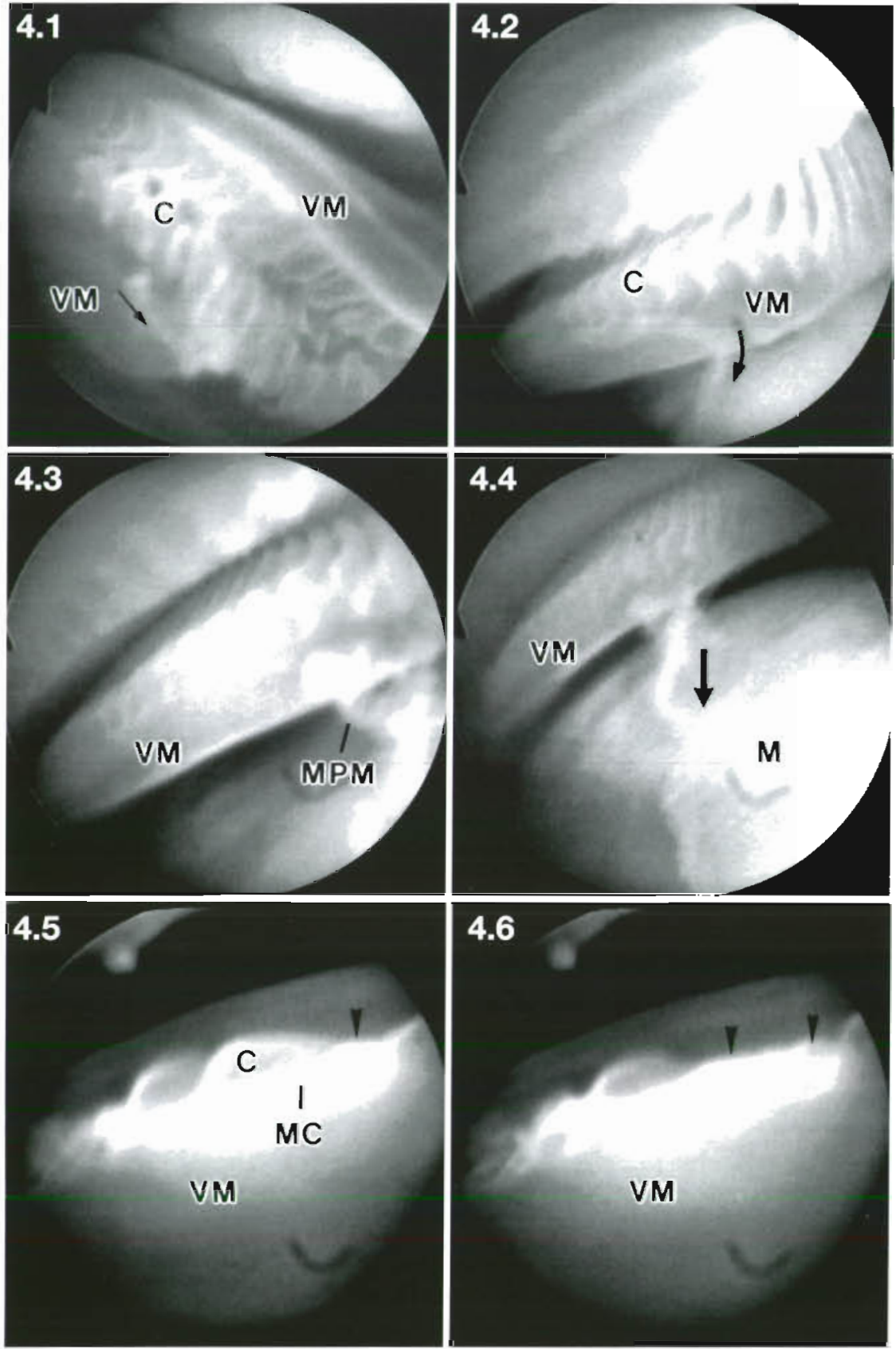

Fig. 4. Mya arenaria and Spisula soldissima. Pallial organs viewed via endoscopy. (4.1) Vlew of palp ventral margins (VM) and crests (C) of $M$ arenaria. Arrow indicates posteriorlydirected mucus-particle masses. (4.2) Palp ventral margin (VM) of $M$. arenaria, with detachment of mucus cord (arrow). C: crest. (4.3) Mucus-particle mass (MPM) accumulating at palp ventral margin (VM) of $M$ arenaria (4.4) Transfer of mucus-particle cord (arrow) from the palp ventral margin (VM) to the mantle (M) of $M$. arenaria. $(4.5,4.6)$ View of palp ventral margin (VM) and crests (C) of $S$. solidissima. with mucus cord ( $\mathrm{MC}$ ) temporarily de taching and crests contracting farrowheads) to return mucus cord to ventral margin the palp to ingestion. The opening and closing of the lower lip was similar to that observed for Spisula solidissima.

In the buccal region, excess material accumulated at the anterior junction of the palp and upper lip, where it was progressively transformed into a viscous mass and. eventually caught by the cilia of the palp ventral margin. The excess material then moved posteriorly to join the rejection cord.

Rejection was clearly observed after prolonged feeding; in separated palps mucus-particle cords from the gill particle groove were directly transported obliquely over the palp crests to the palp ventral margin. At this point they were incorporated into a viscous mucusparticle cord travelling posteriorly toward the posteriormost extremity of the palp (Figs. 4.1, 4.2, 4.3, 6.2). In appressed palps, small mucus-particle masses exited the crest troughs to join the posteriorly-moving mucusparticle cord along the palp ventral margin (Fig 6.2). These smaller masses may have originated from a rejection cord which was fragmented by the mechanical action of the appressed palps, although this cannot be confirmed due to the observational constraints previously mentioned. 


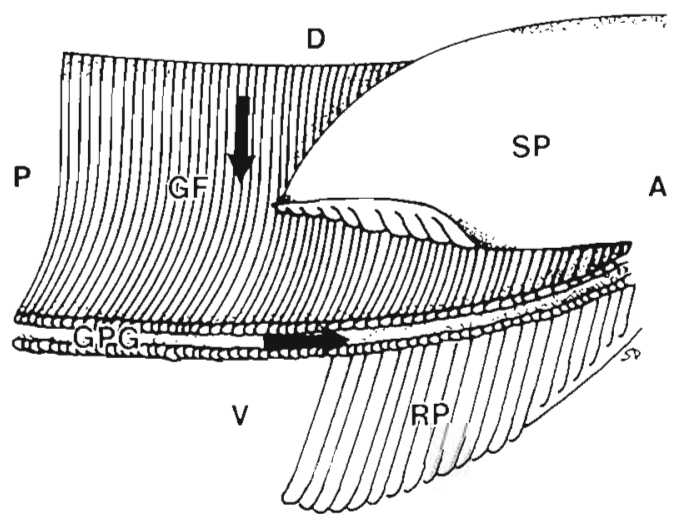

Fig. 5. Mya arenaria. Natural configuration of pallial organs and particle trajectories on gill. Arrows indicate direction of mucus-particle masses along gill filaments (GF) and in gill particle groove (GPG). Dominant pallial currents posteroanterior (P-A) and ventro-dorsal (V-D). RP: ridged palp surface, SP: smooth palp surface

6.1
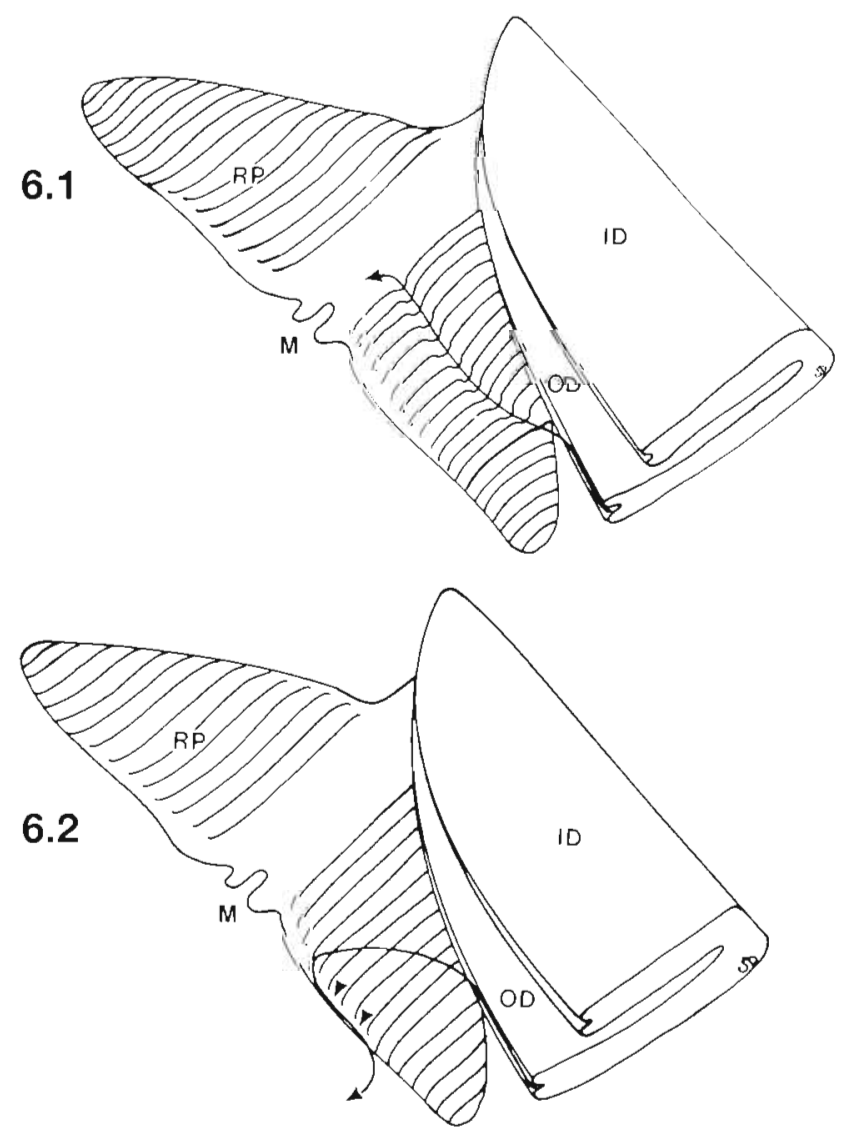

Fig. 6. Mya arenaria. Diagrams of pallial organs with mucusparticle trajectories during ingestion and rejection. Labial palps spread to reveal ridged surface. (6.1) Direction of mucus-particle masses destined for ingestion along ridged palp surface (RP). (6.2) Direction of rejected mucus-particle masses along ridged palp surface (RP). Arrowheads represent small mucus-particle masses exiting troughs and joining mucus cord on the palp ventral margin. ID: inner demibranchi $M$ : mouth; OD: outer demibranch
Upon reaching the posteriormost palp extremity where the ventral palp margin curled slightly (Fig. 5), the cord was transferred from the palp margin either directly to the mantle (Fig. 4.4) or to the mantle after first being deposited on the foot. In every case observed, the mucus-particle cord followed a specific pathway from the point of deposit on the mantle to the inhalent siphon, along the ventral margin of the mantle. This pathway was bounded by a continuous crest on the inner side, and the mantle lobes on the outer side, forming a gutter which acted to isolate the cord of pseudofaeces from the gill margin (Fig. 7).

\section{Particle transport in dissected animals}

Particle trajectories in dissected specimens were similar for both species. Although great care was taken not to disturb the feeding structures, the position of the palps in relation to the gills was distorted to various degrees in different individuals; in addition, the palps were invariably curled along the antero-posterior axis and did not move as in undissected specimens. No change in configuration was observed for the gills.

All particles deposited in the water close to the gills were transported ventrally on the frontal surface to the ventral particle groove. They were then transported anteriorly in the particle groove, although mucus, if present, was not visible.

Particles were transferred from the gill particle groove to the palp ridged surface, where they were

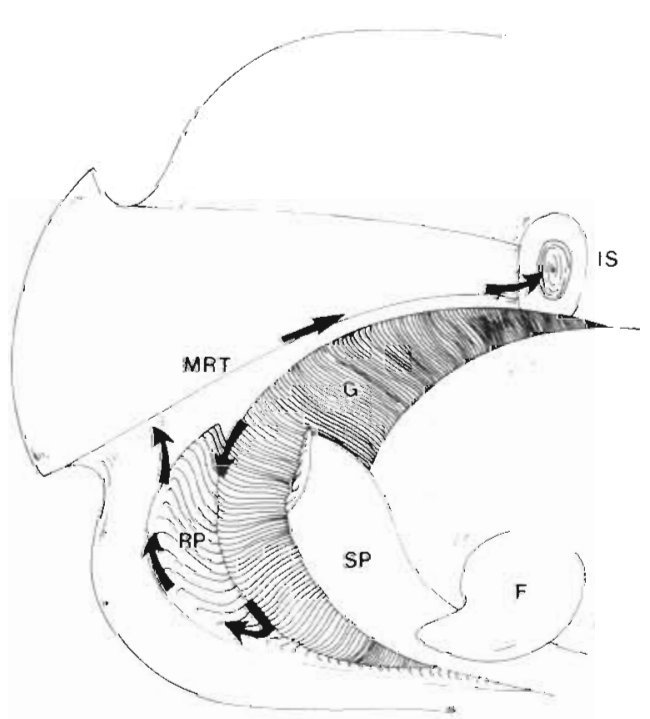

Fig. 7 Mya arenaria. Diagram showing pallal organs and rejection pathway (arrows) on left side of specimen. F: foot; G: gill, IS: inhalent siphon; MRT mantle rejection tract; RP: ridged palp surface; SP: smooth palp surface 

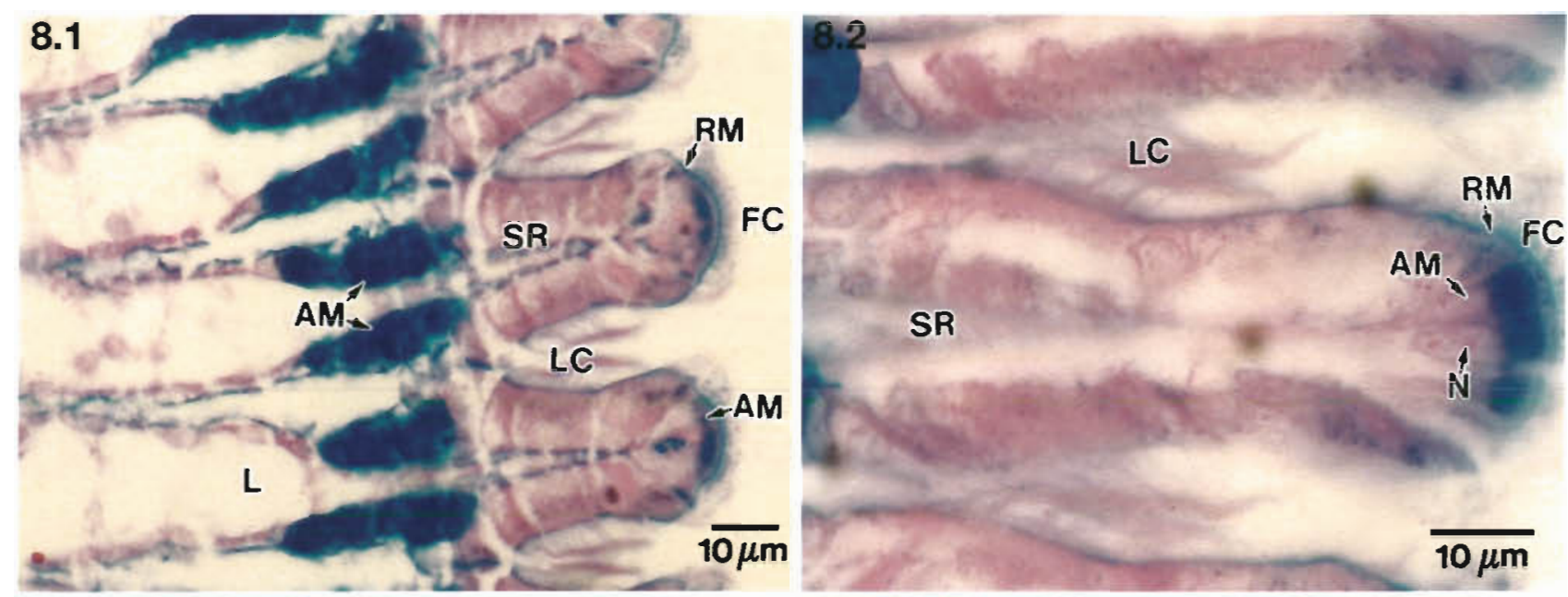

FC
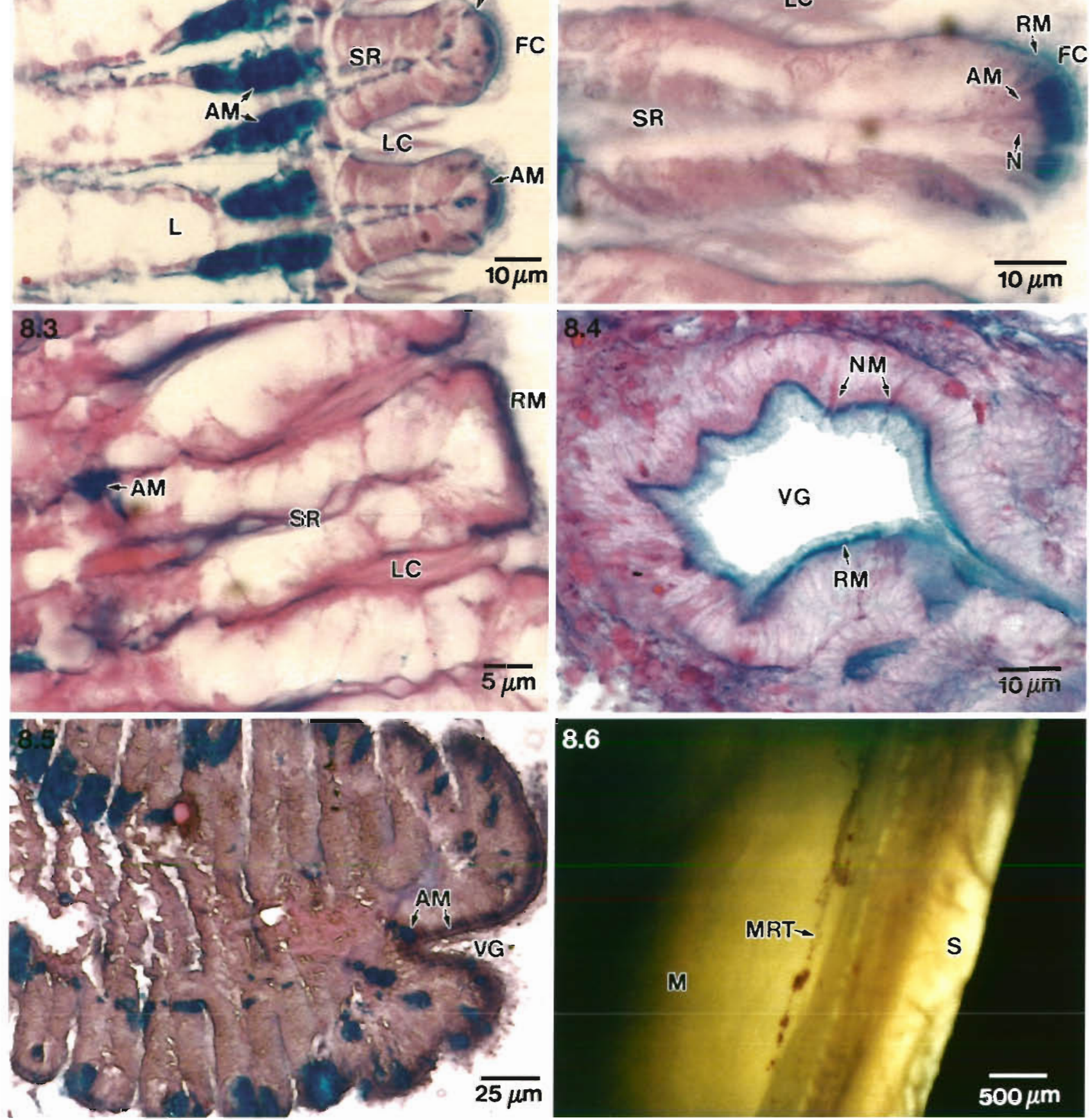

Fig. 8. Spisula solidissima and Mya arenaria. Micrographs of histological sections (8.1-8.5) and of a half-shell preparation (8.6) (8.1) Transverse section through S. solidissima gill filaments. Acid secretion mucocytes (AM) are present on the frontal surface and in glands on the lateral faces of filaments; FC: frontal cilia; L: Iumen; LC: lateral cilia; RM: residual mucus; SR: supporting rods. (8.2) Detail of trontal surface of $S$. solidissima gill filament, showing acid-secretion mucocytes (AM). FC: frontal cilia; LC: lateral cilia; N: nucleolus within nucleus; RM: residual mucus; SR: supporting rods. (8.3) Transverse section through $M$. arenaria gill filaments. Acid-secretion mucocytes (AM) are present at the lateral faces of the filaments. LC: lateral cilia; RM: residual mucus; SR: supporting rods. (8.4) Longitudinal section through a ventral groove (VG) of $M$. arenaria. Neutral-secretion mucocytes (NM) can be seen, as well as residual AMPS (RM). (8.5) Longitudinal section of a $S$. solidissima gill, showing the ventral groove (VG) and associated acid-secretion mucocytes (AM). (8.6) In vivo photograph of the mantle margin of S. solidissima, showing a carmine-mucus cord in the mantle rejection tract (MRT). M: mantle; S: shel 
seen to exit the troughs and join the palp ventral margin. On the ventral palp margin tract the mucusparticle masses travelled to the posterior extremity, and from there to the mantle. The masses proceeded in a distinct, thin line, located just inside the ventral mantle margin, toward the inhalent siphon (Fig. 8.6).

\section{Histology}

\section{Spisula solidissima}

The mucocytes within the frontal epithelium of Spisula solidissima contained entirely acid mucopolysaccharides (AMPS) (Fig. 8.1, 8.2). In addition, dense concentrations of AMPS mucocytes were located on the lateral faces of the filaments, below the lateral cilia (Fig. 8.1). Alcian-blue-positive secretions originating from these mucocytes extended along the external face of the epithelium (water canal) toward the abfrontal region of the filament. Abfrontal mucocytes were also entirely AMPS. Ventrally the frontal mucocytes became larger and more numerous, and the ventral particle groove epithelium also contained many AMPS mucocytes/mucus-containing sites (Fig. 8.5)

On the frontal surface of the filaments, alcian-bluepositive residual mucus was visible in the layer of frontal cilia, but not on the exposed lateral surface of the filament (Fig. 8.1, 8.2).

\section{Mya arenaria}

The only mucocytes observed in the Mya arenaria frontal epithelium were AMPS cells located on either side of the gill filament, below the lateral cilia and above the inter-filamentar junction (Fig. 8.3). These mucocytes resembled the more numerous ones of Spisula solidissima at the same position. Abfrontal mucocytes were sparse in Mya arenaria compared to $S$. solidissima. The gill ventral particle groove epithelium presented a few neutral mucopolysaccharide(NMPS) containing mucocytes (Fig. 8.4) and residual AMPS.

As observed in Spisula solidissima, the frontal cilia of the filaments were lined with alcian-blue-positive residual mucus (Fig. 8.3), as was the gill ventral particle groove (Fig. 8.4). Although a small amount of alcian-blue stain was also present on the lateral faces of the filaments, this may have been unreacted stain which was trapped both in the small interfilamentar space and the lateral cilia (Fig. 8.3, 8.4).

No external supporting rods (as reported by Yonge 1923) were found in the gill of Mya arenaria.

\section{DISCUSSION}

\section{Initial transport and processing for ingestion}

The ventralward movement of all captured particles to the gill ventral particle groove, and subsequent transport oralward in both species, conforms to that previously reported for the eulamellibranchs Mya arenaria and Pyganodon cataracta using endoscopy (Ward et al. 1991, 1993, Tankersley \& Dimock 1993). The behavior of particles deposited on the gills of dissected specimens was similar to this in both species, indicating that the eulamellibranch gill is much less susceptible to malfunction under these conditions than the heterorhabdic filibranch gill (see Beninger et al. 1988,1992 ). Indeed, the eulamellibranch gill is a much more unified structure, with little possibility of deformation (and hence more amenable to study of isolated gill portions, as in Silverman et al. 1996, Beninger et al. in press).

The behavior of particles in the ventral particle groove was consistent with that of particles embedded in a relatively viscous mucus cord (see Ward et al. 1994): the 'bridge' formed by this cord to the ridged surface of the labial palps in Mya arenaria conforms to that observed in Pyganodon cataracta (Tankersley \& Dimock 1993) and Crassostrea virginica (Ward et al. 1994). It seems likely, therefore, that such a mucus bridge is characteristic of transfer between a gill with a ventral particle groove and a palp without a dorsal fold. In contrast, the transfer is direct in Mytilus edulis, which presents a palp dorsal fold (Beninger \& St-Jean 1997).

The subsequent processing for ingestion of the transferred mucus-particle cord was described for dissected Mya arenaria in an early study by Yonge (1923); this was greatly modified by the observations of FosterSmith (1978), who used the shell-window technique, which only allowed observation when the palps spontaneously separated. The formation of ephemeral ciliated tracts from localized depressions in successive palp crests is here confirmed. Although it was not possible to follow a cord throughout its processing due to the proximity of the palp ridged surfaces to each other for much of their length, it was possible to reconstruct this processing by observing the state of transferred cords at various positions along the postero-anterior axis of the palps. The progressive fluidization of this cord as it proceeds anteriorly is in accordance with the observations of Ward et al. (1994) for Crassostrea virginica and Beninger \& St-Jean (1997) for Mytilus edulis; as stated in these previous studies, fluidization is a necessary prerequisite to particle selection, and ingestion appears to occur in such a medium. Disruption of the cord may be aided by the mechanical action 
of the appressed palp crests and by the successive transfer between crests, but it might also involve a chemical reduction in viscosity as was observed in $M$. edulis (Beninger \& St-Jean 1997). Mucocyte mapping of the palps might resolve this question.

In the present work, it was not possible to observe selection (differential treatment of particles extracted from the fluidized slurry), as the proximity of the ridge crests in Mya arenaria obstructed observation of the troughs, where rejected particles may have been shunted (Foster-Smith 1978)

The opening and closing behavior of the lower lips in both Mya arenaria and Spisula solidissima demonstrates that these organisms are capable of discontinuous ingestion. A totally different mechanism of discontinuous ingestion. was reported for Crassostrea virginica, based on ciliary band activation (Ward et al. 1994). There may be a diversity of such mechanisms in various bivalve types; the advantage of discontinuous ingestion is that it permits an ultimate stage of both ingestion volume regulation (see below) and selection.

\section{Origin and role of mucus}

The recent objection that the endoscopic technique might engender artefactual mucus production (Jørgensen 1996 ) is untestable however, as previously explained (Ward et al 1991), great care is taken to ensure normal feeding behavior (normal shell gape, siphons and tentacles extended, pallial flow and particle movement in pallial cavity maintained). Moreover, the convergent data generated using very different techniques (endoscopy, mucocyte mapping, chemical and histochemical analysis of pallial fluid aspirates) should be balanced against the assertion that no mucus is involved in normal feeding, based on the single visual conclusion of lack of particle cohesiveness in oesophagus (and probably also gut) contents (Kiørboe \& Møhlenberg 1981). Moreover, earlier manipulations of this type by Bernard (1974) led to the conclusion that mucus was indeed present in the oesophagus, and the histological data of Beninger et al. (1991) showed the dense, actively-secreting mucocyte distribution in the oesophagus of 5 bivalve species fixed within $30 \mathrm{~s}$ of the initial cut

The presence of mucus on the bivalve gill is underestimated using endoscopy, since mucus itself is transparent and only becomes visible when clumped or when it contains reflective particles. The concentration of such particles is much lower on the gill surface than in the gill particle groove, so mucus is more readily observed there. As mentioned above, the behavior of particles in the gill ventral particle groove of both species is consistent with transport in mucus, and the gill- palp transfer observed in Mya arenaria clearly demonstrates the mucus 'bridge'. In addition, the residual AMPS in the particle groove cilia support the hypothesis of mucus transport. Whereas in Spisula solidissima the origin of this mucus is easily found in the filament frontal AMPS mucocytes and those of the ventral particle groove, the situation in $M$. arenaria seems more complex. A thorough search throughout the gill showed that the AMPS mucocytes situated on the lateral faces of the filaments at the interfilamentar junctions are the only possible sites for the mucus used in particle transport on the gill. These mucocytes may be a reduced form of the corresponding mucocytes in $S$. solidissima, providing secretions which act to reduce drag in the water canals, similar to the role of viscous mucus on the fish epidermis (Hoyt 1975, Daniel 1981). It is highly unlikely that mucus secreted here would also be transported along the exterior of the filament to the frontal surface, since the lateral cilia beat in the opposite direction, and are separated from the laterofrontal cirri by non-ciliated cells. We must therefore consider the possibility that these mucocytes form part of a gland system capable of secreting directly onto the frontal surface. The presence of residual mucus in the frontal cilia strongly suggests that mucus is indeed secreted onto the frontal surface, and not the lateral surface where the mucocytes are actually located. Verification of the existence of such a gland system will require meticulous investigation.

The gills of both species are remarkably small compared to those found in filibranchs or pseudolamellibranchs, and it may be that the mucocytes are situated at the only location where there is room for them. Research in progress seeks to further elucidate this problem, which is not confined to Mya arenaria: a similar situation exists for Mercenaria mercenaria (authors unpubl. obs.) and Dreissena polymorpha (Silverman et al. 1996).

As outlined above, mucus is utilized in various states of viscosity in all stages of particle transport and processing, as has been observed in all other species examined to date using endoscopy and mucocyte mapping (see Beninger \& Dufour 1996, Beninger \& St-Jean in press for review and references). In particular, high-viscosity secretions rich in AMPS seem to be employed universally in transport to the ventral bend of the gill, counter to the prevailing current (Beninger et al. 1993, Beninger \& Dufour 1996, Beninger \& St-Jean in press). The occasional NMPS mucocytes found in the gill ventral particle groove of Mya arenaria contain low-viscosity secretions (Grenon \& Walker 1980, Moreno et al. 1982) which could not account for the 'bridge' observed during gill-palp transfer; they may play a role in the preparation of the mucus-particle cord for eventual fluidization on the palp ridges (see Beninger \& St-Jean 1997). 


\section{Ingestion volume regulation and pseudofaeces formation}

Whereas respiration is a continuous requirement in physiologically active bivalves, feeding is not, especially under conditions of particle saturation (phytoplankton blooms, high resuspended seston loads, etc.). It is thus necessary for suspension-feeding bivalves to possess mechanisms of uncoupling these 2 physiological functions; we designate this 'ingestion volume regulation' (Beninger et al. 1992).

In contrast to the filibranch condition, the eulamellibranch gill is a much more homogeneous and integral stucture. In particular, its dorsal fusion with the mantle and lateral interfilamentar fusion preclude most of the ingestion volume regulation mechanisms observed to date in the filibranch gill (Famme \& Kofoed 1983, Famme et al. 1986, Beninger et al. 1992). However, both Mya arenaria and Spisula solidissima were able to close the gill ventral particle grooves after prolonged exposure to the particle concentrations used in these investigations, effectively shutting down the feeding function of the gill. A similar mechanism has been described for the pseudolamellibranch Crassostrea virginica (Ward et al. 1994).

A second site and mechanism of ingestion volume control was found on the palps of Mya arenaria and Spisula solidissima. After $30 \mathrm{~min}$ exposure to the medium particle concentration, whole mucus cords transferred from the gill ventral particle groove to the labial palps were shunted to the palp ventral margin. This behavior was observed in tandem with the closing of the ventral particle groove (see above). This common rejection pathway also operates in the homorhabdic filibranch Mytilus edulis, the heterorhabdic filibranch Placopecten magellanicus (Beninger \& St-Jean 1997), and the heterorhabdic pseudolamellibranch Crassostrea virginica (Ward et al. 1994); it may thus be a universal feature in suspension-feeding bivalves. Although Foster-Smith (1978) stated that material on the palp ventral margin could be returned to the palp ridges for eventual acceptance, this was never observed in $M$. arenaria or $S$. solidissima of the present study; indeed, the latter species presented an efficient mechanism of returning any mucus cords which began to stray toward the ridges. We may thus conclude that all material on the palp ventral margin is pseudofaeces destined for voidance. Again, the highly viscous nature of the mucus-particle masses on this pathway corresponds to counter-current transport on a relatively exposed surface.

As mentioned above, a final site of ingestion volume control is provided by the lower lips of both species examined here; excess or negatively-selected material accumulates here and is eventually caught by the palp cilia and shunted to the rejection pathway. It is thus clear that, as in all other species examined endoscopically to date, these 2 eulamellibranchs possess a multi-level means of controlling ingestion volume.

\section{Pseudofaeces transport and voidance}

The specific mantle rejection tract observed in both Mya arenaria and Spisula solidissima extended along the ventral margin from the posterior palp region to the inhalent siphon. Previous reports of such a tract were made on several species of dissected specimens (Wallengren 1905, Orton 1912, Kellogg 1915, Ansell 1961). In the present study, the mantle rejection tract remained functional after dissection, indicating a large degree of nervous autonomy. The intervention of the foot for transfer to the mantle in $M$. arenaria confirms the early observations of Kellogg (1915) on dissected specimens. This author also reported erectile ridges along the pseudofaeces pathway in several eulamellibranchs, excluding $M$. arenaria; the present study confirms the existence of such a ridge in the latter species as well.

The requirement for a discrete mantle rejection tract appears to be related to the presence of a gill ventral particle groove and siphons. Since in bivalves presenting these attibutes all captured particles are transported to the palps, and essentially all pseudofaeces are formed there, an efficient mechanism is required for the transport of pseudofaeces from the postero-ventral palp margin to the exterior access (siphons), situated at the opposite pole of the organism. A similar tract has been observed using both endoscopy and carmine particles on dissected specimens of Mytilus edulis (Beninger \& St-Jean in press), although in $M$. edulis the tract was situated much more dorsally. In all cases the tract was located in the infrabranchial chamber of the pallial cavity; since all particle interception occurs there, and the only communication of this chamber with the exterior is via the inhalent siphon, pseudofaeces must therefore be transported on the exposed mantle surface, counter to the prevailing pallial current, to the inhalent siphon for voidance to the exterior. In Mya arenaria the tract seems to be somewhat protected by the continuous ridge formed by the mantle on the medial side of the tract and by the mantle lobes on the distal side. Such a tract does not exist in Placopecten magellanicus, which has no siphons and voids pseudofaeces from the general mantle surface via valve clapping (Beninger \& St-Jean in press). 


\section{Particle processing in intact versus dissected specimens}

As mentioned above, particle transport on the gill was similar in intact specimens examined using endoscopy and in dissected specimens with particles deposited directly on the gill frontal surface. Whereas in the former situation, particle concentration in the external milieu can be modulated to simulate natural conditions, this is not possible with dissected animals which can no longer naturally draw particles into the pallial cavity. Similarly, the greatly-modified anatomical relationships of the pallial organs precludes the study of processing for ingestion. Rejection pathways were similar in both types of preparations, so we may conclude that dissected specimens can be used for the rudimentary observation of particle pathways on the eulamellibranch gill and for rejection pathways on the other pallial organs. Such information may occasionally be useful in situations where endoscopy is impossible (e.g. the palps of Pectinidae, see Beninger \& St-Jean 1997) and in teaching laboratories. Otherwise, endoscopy, mucocyte mapping, ultrastructural techniques, and confocal laser microscopy are indispensable and complementary tools for the study of suspension-feeding mechanisms in bivalves.

Acknowledgements. We thank MM. L. Blanchard and N Vienneau for patient assistance with video-to-still transfer. and $\mathrm{Dr} \mathrm{H}$. Silverman for stimulating discussions and criticism. This work was funded by operating grants from the Université de Moncton and the Natural Sciences and Engineering Research Council of Canada

\section{LITERATURE CITED}

Ansell AD (1961) The functional morphology of the British species of Veneracea (Eulamellibranchia). J Mar Biol Assoc UK 41:489-515

Atkins D (1937) On the ciliary mechanisms and interrelationships of lamellibranchs. Part III: types of lamellibranch gills and their food currents. Q J Microsc Sci 79:375-420

Atlas RM, Bartha, A (1987) Microbial ecology: fundamentals and applications, 2nd edn. The Benjamin/Cummings Publishing Co., Menlo Park, CA

Beninger PG, Dufour SC (1996) Mucocyte distribution and relationship to particle transport on the pseudolamellibranch gill of Crassostrea virginica (Bivalvia: Ostreidae). Mar Ecol Prog Ser 137:133-138

Beninger PG, Le Pennec M (1993) Histochemistry of the buccooesophageal glands of Mytilus edulis: the importance of mucus in ingestion. J Mar Biol Assor UK 73:237-240

Benunger PG, Le Pennec M. Donval A (1991) Mode of particle ingestion in five species of suspension-feeding bivalve molluscs. Mar Biol 108:255-261

Beninger PG, Le Pennec M, Salaün M (1988) New observations of the gills of Placopecten magellanicus (Mollusca: Bivalvia) and implications for nutrition. I. General anatomy and surface microanatomy. Mar Biol 98.61-70
Beninger PG, Lynn JW, Dietz TH, Silverman $H$ (in press) Mucociliary transport in living tissue: the two-layer model confirmed in the mussel Mytilus edulis L. Biol Bull

Beninger PG. St-Jean SD (1997) Particle processing on the labial palps of Mytrlus edulis and Placopecten magellanicus (Mollusca: Bivalvia). Mar Ecol Prog Ser 147:117-127

Beninger PG, St-Jean SD (in press) The role of mucus in particle processing by suspension-feeding marine bivalves: unifying principles. Mar Biol

Beninger PG, St-Jean S, Poussart Y, Ward JE (1993) Gill function and mucocyte distribution in Placopecten magellanicus and Mytilus edulis (Mollusca: Bivalvia): the role of mucus in particle transport. Mar Ecol Prog Ser 98:275-282

Beninger PG, Ward JE, MacDonald BA, Thompson RJ (1992) Gill function and particle transport in Placopecten magellanicus (Mollusca: Bivalvia) as revealed using video endoscopy. Mar Biol 114:281-288

Dame R, Zingmark R, Stevenson $H$, Nelson D (1980) Filterfeeder coupling between the estuarine water column and benthic subsystems. In: Kennedy VS (ed) Estuarine perspectives. Academic Press, New York, p 521-526

Daniel TL (1981) Fish mucus: in situ measurements of polymer drag reduction. Biol Bull 160:376-382

Famme P, Kofoed LH (1983) Shunt water flow through the mantle cavity in Mytilus edulis $\mathrm{L}$. and its influence on particle retention. Mar Biol Lett 4:207-218

Famme P, Riisgård HU, Jorgensen CB (1986) On direct measurement of pumping rates in the mussel Mytilus edulis. Mar Biol 92:323-327

Foster-Smith RL (1978) The function of the pallial organs of bivalves in controlling ingestion. J Molluscan Stud 44: $83-99$

Grenon JF, Walker G (1980) Biochemical and rheological properties of the pedal mucus of the limpet, Patella vulgata L. Comp Biochem Physiol 66B:451-458

Hoyt JW (1975) Hydrodynamic drag reduction due to fish slimes. In: Wu TVT, Brokaw CJ, Brennen C (eds) Swimming and flying in nature. Plenum Press, New York, p 653-673

Jørgensen CB (1990) Bivalve filter-feeding: hydrodynamics, bioenergetics, physiology and ecology. Olsen and Olsen, Fredensborg

Jørgensen CB (1996) Bivalve feeding revisited. Mar Ecol Prog Ser 142:287-302

Kellogg JL (1915) Ciliary mechanisms of lamellibranchs with descriptions of anatomy. J Morphol 26:625-701

Kiørboe T, Mohlenberg F (1981) Particle selection in suspension-feeding bivalves. Mar Ecol Prog Ser 5:291-296

Moreno FJ, Pinere J, Hidalgo J, Navas P, Aijon J, LopezCampos JL (1982) Histochemical and ultrastructural studies on the saljvary glands of Helix aspersa (Mollusca) J Zool (Lond) 196:343-354

Orton JH (1912) The mode of feeding of Crepidula, with an account of the current-producing mechanism in the mantle cavity, and some remarks on the mode of feeding in Gastropods and Lamellibranchs. J Mar Biol Assoc UK 9:444-478

Riisgård HU (1988) Efficiency of particle retention and filtration rate in 6 species of Northeast American bivalves. Mar Ecol Prog Ser 45:217-223

Silverman $H$, Achberger EC, Lynn JW, Dietz TH (1995) Filtration and utilization of laboratory-cultured bactena by Dreissena polymorpha, Corbicula fluminea, and Carunculina texasensis. Biol Bull 189:308-319

Silverman H, Lynn JW, Dietz TH (1996) Particle capture by the gills of Dreissena polymorpha: structure and function of latero-frontal cirri. Biol. Bull. 191:42-54 
Tankersley RA, Dimock RV Jr (1992) Quantitative analysis of the structure and function of the marsupial gills of the freshwater mussel Anodonta cataracta. Biol Bull 182: $145-154$

Tankersley RA, Dimock RV Jr (1993) Endoscopic visualization of the functional morphology of the ctenidia of the unionid mussel Pyganodon cataracta. Can J Zool 71:811-819

Wallengren $H$ (1905) Zur Biologie der Muscheln. II. Die Nahrungsaufnahme. Kongl Fysiografiska Sällskapets Hand NF 16:1-59

Ward JE, Beninger PG, MacDonald BA, Thompson RJ (1991) Direct observations of feeding structures and mechanisms in bivalve molluscs using endoscopic examination and video image analysis. Mar Biol 111:287-291

Ward JE, MacDonald BA. Thompson RJ, Beninger PG (1993)

This article was submitted to the editor
Mechanisms of suspension-feeding in bivalves: resolution of current controversies by means of endoscopy. Limnol Oceanogr 38:265-272

Ward JE, Newell RIE, Thompson RJ, MacDonald BA (1994) In vivo studies of suspension-feeding processes in the eastern oyster, Crassostrea virginica (Gmelin). Biol Bull 186:221-240

Winter JE (1978) A review on the knowledge of suspensionfeeding in lamellibranchiate bivalves, with special reference to artificial aquaculture systems. Aquaculture 13: $1-33$

Yonge CM (1923) Studies on the comparative physiology of digestion. I. The mechanism of feeding, digestion, and assimilation in the lamellibranch Mya. Br J Exp Biol $1: 15-63$

Manuscript first received: September 23, 1996

Revised version accepted: February 7, 1997 